intravenous amiodarone is safe in patients with atrial fibrillation and WolffParkinson-White syndrome in the emergency department. CJEM 2005;7: 262-5.

7. Brugada P, Brugada J, Mont L, et al. A new approach to the differential diagnosis of a regular tachycardia with a wide QRS complex. Circulation 1991; 83:1649-59.

8. Isenhour JL, Craig S, Gibbs M, et al. Wide-complex tachycardia: continued evaluation of diagnostic criteria. Acad Emerg Med 2000;7:769-73.

9. Herbert ME, Votey SR, Morgan MT, et al. Failure to agree on the electrocardiographic diagnosis of ventricular tachycardia. Ann Emerg Med 1996;27:35-8.

\section{[The authors respond]}

We thank Drs. Healey, Mensour and Marshall for their interest in our diagnostic challenge published in the November 2008 issue of CJEM. ${ }^{1}$ They summarize their comment on our article by stating, "The safest approach for the emergency physician is to treat all wide complex tachycardias as ventricular tachycardia (VT)." As we indicated, ${ }^{1}$ we essentially agree with this point of view, with one notable exception. We welcome the opportunity to further discuss this distinction.

The correspondents posit that "one can rarely be certain of the diagnosis and should routinely proceed with the treatment of wide complex tachycardia as VT" by sedating and shocking the patient. We contend that, in treating a stable patient, supraventricular tachycardia (SVT) with aberrant conduction can be distinguished from VT with sufficient frequency to warrant the effort. Although the default position in uncertain cases is to treat as VT, when the rhythm is SVT with aberrant conduction, the American Heart Association guidelines for emergency care ${ }^{2}$ recommend adenosine as first-line therapy.

Our diagnostic challenge included an electrocardiogram (ECG) showing a regular, wide QRS tachycardia with typical left bundle branch block (LBBB) morphology. The differential diagnosis in this case includes VT and SVT with LBBB. The latter includes sinus tachycardia, true atrial tachycardia, atrioventricular (AV) nodal re-entry and orthodromic reciprocating tachycardia in a patient with Wolff-Parkinson-White (WPW) syndrome (down the normal conduction pathway and up the accessory AV connection); each with LBBB. This tachycardia has less than a $10 \%$ chance of being VT, ${ }^{3}$ and when it is VT, it is often adenosine-sensitive right ventricular outflow tract VT. ${ }^{4}$

Dr. Healey and colleagues suggest that "one still ought to avoid adenosine in these instances." As quoted by the correspondents, adenosine may be dangerous in WPW syndrome patients with pre-excited atrial fibrillation by increasing the frequency of accessory connection conduction of atrial fibrillation, thereby predisposing the patient to the development of ventricular fibrillation (VF). In the cases cited by Dr. Healey and coworkers that converted to VF after receiving adenosine,, 5 all initially presented with preexcited atrial fibrillation. By definition, such rhythms are grossly irregular with atypical aberrancy that should not be mistaken for a regular SVT. This is not meant to imply that adenosine for regular SVT is without risk. One rarely reported risk is conversion of a regular SVT to atrial fibrillation which, in the presence of manifest WPW syndrome, could be conducted at a rapid rate. ${ }^{6}$ Our patient did not have manifest WPW syndrome, as confirmed by history and by previous and follow-up ECGs. We could find only 1 report of VT degenerating into VF after adenosine was given, ${ }^{7}$ and reports of VT degenerating into VF in the absence of adenosine are numerous. ${ }^{8}$ Indeed, adenosine has been recommended as a safe diagnostic aid that can be used to distinguish regular SVT with aberrant conduction from VT. ${ }^{9-11}$ Thus the probability of a serious complication from adenosine in the setting of a regular wide QRS tachycardia is remote ${ }^{12}$ and does not support the correspondents' statement that adenosine in this setting "has grave risks associated with its use." Furthermore, alternative treatments, such as intravenous procainamide and direct current cardioversion, have complications of their own, including ventricular proarrhythmia. Finally, in our patient, treatment with procainamide was not advised as the patient was already on sotalol. Combining 2 agents known to prolong the QT interval might elicit torsades de pointes.

The correspondents conclude by stating, "Let us put the safety of our patients first and the vanity of superior academic skills second." We agree with the first statement and consider the second to be an unfortunate choice of words. Rather than a routine "sedate and shock" approach, we offer an alternative: "think and link" the treatment of a tachydysrhythmia to its evident pathophysiology. Nevertheless, what is ultimately done will depend on local standards of care and the confidence of the clinician in decision-making in the emergency department.

\section{Jason Mitchell, BSc}

Medical Student, University of Calgary Health Region, Calgary, Alta.

\section{Gerald Lazarenko, MD}

Clinical Assistant Professor, University of Calgary, Calgary, Alta.

\section{References}

1. Mitchell J, Lazarenko G. Wide QRS complex tachycardia. CJEM 2008;6: 572-3.

2. ECC Committee; Subcommittees and Task Forces of the American Heart Association. 2005 American Heart Association Guidelines for Cardiopulmonary Resuscitation and Emergency Cardiovascular Care. Circulation 2005;112: IV1-203.

3. Griffith MJ, Garratt CJ, Mounsey P, et al. Ventricular tachycardia as default diagnosis in broad complex tachycardia. 
Lancet 1994;343:386-8.

4. Kim RJ, Iwai S, Markowitz SM, et al. Clinical and electrophysiological spectrum of idiopathic ventricular outflow tract arrhythmias. J Am Coll Cardiol 2007;49:2035-43.

5. Gupta AK, Shah CP, Maheshwari A, et al. Adenosine induced ventricular fibrillation in Wolff-Parkinson-White syndrome. Pacing Clin Electrophysiol 2002;25:477-80.

6. Exner DV, Muzyka T, Gillis AM. Proarrhythmia in patients with WolffParkinson-White syndrome after standard doses of intravenous adenosine. Ann Intern Med 1995;122:351-2.

7. Parham WA, Mehdirad AA, Biermann $\mathrm{KM}$, et al. Case report: adenosine induced ventricular fibrillation in a patient with stable ventricular tachycardia. J Interv Card Electrophysiol 2001;5:71-4.

8. Bayes de Luna A, Coumel P, Leclercq JF. Ambulatory sudden cardiac death: mechanisms of production of fatal arrhythmias on the basis of data from 157 cases. Am Heart J 1989;117:151-9.

9. Rankin AC, Oldroyd KG, Chong E, et al. Value and limitations of adenosine in the diagnosis and treatment of narrow and broad complex tachycardias. Br Heart J 1989;62:195-203.

10. Sharma AD, Klein GJ, Yee R. Intravenous adenosine triphosphate during wide QRS complex tachycardia: safety, therapeutic efficacy, and diagnostic utility. Am J Med 1990;88:337-43.

11. Hina K, Kusachi S, Takaishi A, et al. Effects of adenosine triphosphate on wide QRS tachycardia. Jpn Heart J 1996;37:463-70.

12. Innes JA. Review article: adenosine use in the emergency department. Emerg Med Australas 2008;20:209-15.

\section{A sentinel event for Ontario hospitals}

To the editor: In January of this year, the Huron Perth Healthcare Alliance of 4 Ontario hospitals (Stratford General Hospital, St. Mary's Memorial Hospital, Seaforth Community Hospital and Clinton Public Hospital) announced the reduction in hours of service of one of its emergency departments (EDs). The sole reason for the evening closure is a shortage of registered nurses (RNs). This will be the first time that a hospital ED in Ontario plans to reduce its operating hours for such a reason. It deserves considerable attention, since nursing unions, academic institutions and hospital administrations have been warning for many years that an RN shortage is reaching critical proportions in Ontario. As of Feb. 7, 2009, front-line health care delivery will be visibly and directly affected by this crisis.

The trends and statistics concerning nursing are widely available, and similar to many other professions and trades. They include an aging workforce; declining enrolment in training programs, paradoxically associated with an increased need; and, certainly in the long-term, simple demographics.

Small hospitals with minimal staffing and even less potential back up face the greatest challenge in RN staffing, because a shortage of 1 or 2 nurses can mean the difference between being able to offer a high standard of care, and being unable to offer any care at all.

Hospital administrations do their best to eliminate redundancy, maximize efficiency and optimize use of available human resources. But that does not address the root problem: there are not enough nurses entering the profession to replace those leaving it. It is as simple as that. With an aging population, there will soon be an even greater demand for nurses.

Before this crisis worsens, before more hospitals are obliged to reduce services, or close completely, action must be taken to correct this imbalance. As with the physician shortage, delays in implementing solutions will only mean fewer Ontarians have access to an acceptable quality of health care. Those with a voice at all levels of health care delivery need to make government authorities understand the scale of the problem, and lobby for solutions at a system level. Provincial ministries of economic development, education, health and long-term care, health promotion, labour, training, and colleges and universities need to become part of the solution. A coordinated action plan for encouraging people to enter the nursing profession and seek out careers where they are most needed, for recruiting qualified RNs from other locations around the world and for making the commitment to see such a plan succeed is as necessary a part of health care reform in Ontario as wait time strategies and patient safety indicators. It's time the public became aware of this threat to health care and demand solutions from those who serve the public good.

Perhaps the overnight closure of the ED at the Seaforth Community Hospital can serve as a sentinel event, the "canary in the coal mine" for this crisis, and prompt the kind of commitment to change that health care in Ontario really needs.

\section{Jason Datema, MD}

Site Chief, Seaforth Community

Hospital, Seaforth, Ont.

\section{Advocate or abdicate: the responsible choice for today's emergency medicine resident}

To the editor: I think it can be safely argued that many of the problems that now beset emergency medicine (e.g., crowding, insufficient human resources and service disruptions) are, in part, a result of a lack of advocacy by our specialty during the 1990s when these problems first reared their ugly heads. This is not to lay blame on those who sat on the various executives at that time (I was there until 1994!). It is simply a statement of fact that our specialty and our association lacked organizational maturity at that time and had too many other diversionary issues.

Clearly, if the sins of the fathers are not to be repeated, then it is important that our specialty embrace 